\title{
Use of energy substrates by various stage preimplantation pig embryos produced in vivo and in vitro
}

\author{
J. E. Swain ${ }^{1}$, C. L. Bormann¹, S. G. Clark², E. M. Walters ${ }^{3}$, \\ M. B. Wheeler ${ }^{2}$ and R. L. Krisher ${ }^{1 *}$ \\ ${ }^{1}$ Department of Animal Sciences, Purdue University, West Lafayette, IN 47907-1151, USA; \\ ${ }^{2}$ Department of Animal Sciences and ${ }^{3}$ Beckman Institute for Advanced Science and \\ Technology, University of Illinois, Champaign, IL 61801, USA
}

\begin{abstract}
The aim of in vitro embryo systems is to produce embryos of comparable quality to those derived in vivo. Comparison of embryo metabolism as an indicator of viability may be useful in optimization of culture conditions. The aim of the present study was to determine glucose, glutamine and pyruvate use by various stage pig embryos produced in vitro and in vivo. The results indicate that pig embryos use glucose via glycolysis in significant amounts at all stages examined, regardless of embryo origin. In vitro-derived embryos have significantly increased glycolytic activity after the eight-cell stage, whereas in vivo-derived embryos have increased glycolysis at the blastocyst stage. In vivoderived embryos have higher rates of glycolysis compared
\end{abstract}

\section{Introduction}

The recent successes in cloning and transgenic pig production, and the immense potential these present for xenotransplantation have reaffirmed the need for a more efficient in vitro embryo production system for pigs. Embryo metabolism is a valuable tool for evaluating the efficiency of these in vitro systems. Embryo metabolism may serve as an indicator of embryo viability (Renard et al., 1980; Conaghan et al., 1993; Lane and Gardner, 1996), as well as provide crucial information to support the formulation of a more appropriate culture medium. However, there are relatively few publications describing metabolism of pig embryos. In addition, the developmental competence of in vitro-derived pig embryos is low compared with that of other domestic species.

Understanding the metabolic needs of preimplantation embryos is vital to optimize growth. If the necessary energy substrates are not present in sufficient concentrations or at the appropriate time, the embryo will be unable to develop. One recurring pattern observed in embryo metabolism is increased glycolysis and glucose usage as preimplantation development progresses (Flood and Wiebold, 1988; Thompson et al., 1991; Rieger et al., 1992a,b). However, species-specific preferences are evident. Glucose is

*Correspondence

Email: rkrisher@purdue.edu with in vitro-derived embryos. Glucose usage through the Krebs cycle for in vitro- and in vivo-derived embryos increased significantly at the blastocyst stage. Pig embryos produced in vitro used constant amounts of glutamine throughout development, whereas in vivo-derived embryos increased glutamine usage after the eight-cell stage. Pyruvate use was minimal at all stages examined for both in vitro- and in vivo-derived pig embryos, showing significant increases at the blastocyst stage. Krebs cycle metabolism of pyruvate, glutamine and glucose by in vivo-derived embryos was higher than that by in vitro-derived embryos. Current in vitro culture conditions produce pig embryos with altered metabolic activity, which may compromise embryo viability. inhibitory at all stages of hamster embryo development (Schini and Bavister, 1988a; Seshagiri and Bavister, 1989). Glucose can also have an inhibitory effect on murine (Chatot et al., 1989, 1990) and bovine (Kim et al., 1993) embryos when present before the maternal-zygotic transition. Developing murine embryos prefer pyruvate as their main energy source until they reach the blastocyst stage (Leese and Barton, 1984), whereas lactate is essential for development of hamster (McKiernann et al., 1991) and bovine (Rosenkrans et al., 1993) embryos. Amino acids serve as an additional energy source for developing embryos. Glutamine is important in the transition through the developmental block in hamster embryos (Carney and Bavister, 1987). Mouse embryos increase glutamine usage throughout development (Gardner et al., 1989; Chatot et al., 1990). There is a significant increase in glutamine metabolism accompanying blastocyst expansion in bovine embryos (Rieger et al., 1992b).

Lactate inhibits preimplantation development of pig embryos (Davis and Day, 1978; Davis, 1985) and pyruvate is not necessary for development to the blastocyst stage (Petters et al., 1990; Petters and Reed, 1991). Both glucose and glutamine, alone or in combination, can support preimplantation development of pig embryos (Petters et al., 1990). Glucose is metabolized equally via aerobic and anaerobic pathways by early cleavage stage pig embryos developed in vivo, although glycolysis becomes the dominant pathway as development progresses (Flood and 
Weibold, 1988). From this information, it is evident that pig embryos have changing metabolic needs as they develop and undergo the accompanying morphological and biochemical changes associated with growth, such as the maternal-zygotic transition, compaction and blastocoel development.

There are many differences between embryos produced in vitro and in vivo. In vitro-derived embryos show delayed development, altered cell number and allocation, and altered morphology (for a review, see Thompson, 1997). Usage of substrates by in vitro-and in vivo-derived embryos also differs in some species (Thompson, 1991; Khurana and Niemann, 2000). In vitro-derived embryos tend to have increased glycolytic activity at early cleavage stages and increased lactate production compared with their in vivo counterparts, which alters normal redox potential and intracellular $\mathrm{pH}$ (Gardner and Leese, 1990). This is probably the result of suboptimal maturation, fertilization or culture conditions. However, all metabolic measurements are conducted in an in vitro environment so the physiological metabolism in vivo may differ. The aim of the present study was to examine glucose usage through glycolysis and the Krebs cycle, and glutamine and pyruvate usage through the Krebs cycle, of in vitro- and in vivo-derived pig embryos at the two-cell, eight-cell, morula and blastocyst stages of development.

\section{Materials and Methods}

\section{In vitro maturation}

Pig ovaries were obtained from a local abattoir and transported in $0.9 \%(\mathrm{w} / \mathrm{v})$ saline at a temperature of approximately $30^{\circ} \mathrm{C}$. Oocytes were collected from antral follicles $3-8 \mathrm{~mm}$ in diameter using a $10 \mathrm{ml}$ syringe or aspiration pump (10 $\mathrm{mm} \mathrm{Hg} ; 28 \mathrm{ml} \mathrm{min}^{-1}$ ) and an 18-gauge needle. Cumulus-oocyte complexes (COCs) with at least two layers of compact cumulus cells and even cytoplasm were washed twice in synthetic oviductal fluid (SOF) Hepes-buffered medium supplemented with 1.0\% (v/v) PSA (100 U penicillin $\mathrm{ml}^{-1}, 100 \mu \mathrm{g}$ streptomycin $\mathrm{ml}^{-1}, 0.25 \mathrm{ng}$ amphotericin $\mathrm{ml}^{-1}$; GibcoBRL, Grand Island, NY). Selected COCs were matured (50 per $500 \mu \mathrm{l}$ ) in four-well plates (Nunc, Roskilde) covered with $400 \mu \mathrm{l}$ mineral oil (Sigma, St Louis, MO). Maturation medium (Abeydeera et al., 1998) was completely defined TCM199 medium (Gibco) supplemented with $0.01 \mathrm{U}$ pig $\mathrm{LH} \mathrm{ml}^{-1}$ and FSH (Sioux BCHM, Sioux Center, IA), 10 ng epidermal growth factor $\mathrm{ml}^{-1}$ (EGF; Sigma), $0.91 \mathrm{mmol}$ pyruvate $\mathrm{I}^{-1}$ (Sigma), $0.57 \mathrm{mmol}$ cysteine $\mathrm{I}^{-1}$ (Sigma), $3.05 \mathrm{mmol}$ glucose $\mathrm{I}^{-1}$ (Sigma), 1.0\% (v/v) PSA and $0.01 \%$ (w/v) polyvinylalcohol (PVA; Sigma). Oocytes were matured for $45-47 \mathrm{~h}$ in $5 \% \mathrm{CO}_{2}$ in air at $39^{\circ} \mathrm{C}$. No selection was performed after maturation.

\section{In vitro fertilization}

Frozen pelleted semen was thawed and washed in $10 \mathrm{ml}$ Dulbecco's phosphate buffered saline (D-PBS; Gibco) without $\mathrm{CaCl}_{2}$, supplemented with $1.0 \%$ (v/v) PSA at $39^{\circ} \mathrm{C}$ and centrifuged at $1000 \mathrm{~g}$ for $4 \mathrm{~min}$. The supernatant was decanted and the spermatozoa were washed two additional times in $10 \mathrm{ml}$ D-PBS. Sperm concentration was determined using a haemocytometer and adjusted to $1.0 \times 10^{7}$ spermatozoa $\mathrm{ml}^{-1}$ using modified Tris-buffered medium (mTBM; Abeydeera and Day, 1997) supplemented with

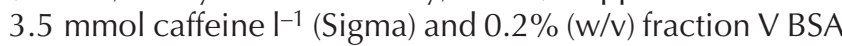
(Sigma). The spermatozoa were preincubated for $2.5 \mathrm{~h}$ in $5 \% \mathrm{CO}_{2}$ in air at $39^{\circ} \mathrm{C}$ to facilitate capacitation. Oocytes were denuded after maturation in SOF Hepes-buffered

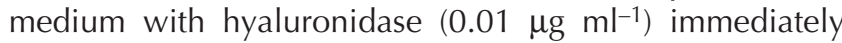
before fertilization and placed (20 oocytes per $50 \mu$ ldroplet) in mTBM. Oocytes were fertilized by adding $50 \mu \mathrm{l}$ of the sperm suspension to the droplets containing oocytes to give a final concentration of $5.0 \times 10^{6}$ spermatozoa $\mathrm{ml}^{-1}$. Oocytes were fertilized for $4 \mathrm{~h}$ in $5 \% \mathrm{CO}_{2}$ in air at $39^{\circ} \mathrm{C}$. No selection was performed after fertilization.

\section{In vitro culture}

Presumptive zygotes were washed vigorously three times in culture medium to remove excess spermatozoa and cultured (8-10 per $50 \mu \mathrm{l}$ droplet) under mineral oil in NCSU23 (Petters and Wells, 1993; 5.55 mmol glucose $\mathrm{I}^{-1}$, $7.0 \mathrm{mmol}$ taurine $\mathrm{I}^{-1}, 1.0 \mathrm{mmol}$ glutamine $\mathrm{I}^{-1}$ ) without hypotaurine supplemented with $0.4 \%(\mathrm{w} / \mathrm{v})$ Pentex BSA (Serologicals, Kanakee, IL) in 5\% $\mathrm{CO}_{2}, 10 \% \mathrm{O}_{2}$ and $85 \% \mathrm{~N}_{2}$ at $39^{\circ} \mathrm{C}$. Embryos were divided randomly into four dishes, one for each cell stage to be examined. Embryos were cultured for 20-22 h, 78-80 h, 118-120 h or $144 \mathrm{~h}$ to obtain two-cell, eight-cell, morula or blastocyst stage embryos, respectively.

\section{In vivo embryo recovery}

Prepubertal gilts $(n=30)$ were synchronized with injections of PG600 ${ }^{\circledR}$ (Intervet, Millsboro, DE) at day 200 of age. The gilts were injected with 1000 iu hCG. Sows $(n=6)$ were checked daily for signs of natural oestrus. Embryo donors were artificially inseminated twice at $12 \mathrm{~h}$ intervals when in standing oestrus. Sows were inseminated 5-7 days after weaning. At the time of embryo flushes, the pigs were anaesthetized with an initial i.m. injection of $6 \mathrm{ml}$ of an anaesthetic combination consisting of Ketaset ${ }^{\circledR}$ (Fort Dodge Animal Health, Fort Dodge, IA; $5.9 \mathrm{mg} \mathrm{kg}^{-1}$ ), Telazol ${ }^{\circledR}$ (Fort Dodge; $12.9 \mathrm{mg} \mathrm{kg}^{-1}$ ) and Rompun ${ }^{\circledR}$ (Bayer, Shawnee Mission, KS; $0.06 \mathrm{mg} \mathrm{kg}^{-1}$ ), followed by a $4 \mathrm{ml}$ i.v. injection via the ear vein. Small endotracheal tubes $(7.0-7.5 \mathrm{~mm}$ inner diameter) were inserted into the nose to be connected to an anaesthesia apparatus, supplying oxygen $\left(2 \mid \mathrm{min}^{-1}\right)$ and $5 \%$ halothane. A ventral mid-line approach was performed and embryos were flushed from the oviduct or uterus, depending on the cell stage, with Beltsville embryo culture media (BECM-3; Dobrinsky et al., 1996) at $39^{\circ} \mathrm{C}$. A three-layer closure of the incision was performed on embryo donors. Embryos were flushed at day 2, 4, 5 or 6 
after oestrus to obtain two-cell, eight-cell, morula or blastocyst stage embryos, respectively. Surgical embryo recovery procedures were approved by the University of Illinois and Purdue University Animal Care and Use Committees.

\section{Metabolic measurements}

Embryos were washed and placed in a $50 \mu$ droplet of modified SOF-based metabolism medium containing $6.0 \mathrm{mmol}$ glucose $\mathrm{I}^{-1}, 0.1 \mathrm{mmol}$ taurine $\mathrm{I}^{-1}, 1.0 \mathrm{mmol}$ glutamine $\mathrm{I}^{-1}, 0.065 \mathrm{mmol}$ pyruvate $\mathrm{I}^{-1}$ and $0.01 \%(\mathrm{w} / \mathrm{v})$ PVA (Sigma) covered in mineral oil (Sigma). Metabolism medium was formulated to resemble energy substrate concentrations in NCSU23 culture medium. Embryo metabolism was measured using a modification of the hanging-drop technique, described and validated by O'Fallon and Wright (1986) and Rieger et al. (1992a,b). The labelled substrates used included pyruvic acid, Na salt [2-C ${ }^{14}$ ] $\left(0.257 \mathrm{mmol} \mathrm{I}^{-1}\right.$, specific activity $0.0045 \mu \mathrm{Ci} \mu \mathrm{l}^{-1}$; American Radiolabeled Chemicals, St Louis, MO), L-[2,3,4$\left.{ }^{3} \mathrm{H}\right]$ glutamine $\left(0.005 \mathrm{mmol}^{-1}\right.$, specific activity $0.25 \mu \mathrm{Ci}$ $\left.\mu \mathrm{I}^{-1} ; \mathrm{ARC}\right)$ and $\mathrm{D}-\left[6{ }^{14} \mathrm{C}\right]$ glucose $\left(0.5 \mathrm{mmol} \mathrm{I}^{-1}\right.$, specific activity $0.028 \mu \mathrm{Ci}_{\mu \mathrm{I}^{-1}}$; ARC) to measure Krebs cycle activity and $\mathrm{D}-\left[5{ }^{3} \mathrm{H}\right]$ glucose to measure glycolysis $(0.016 \mathrm{mmol}$ $\mathrm{I}^{-1}$, specific activity $0.25 \mu \mathrm{Ci} \mu \mathrm{I}^{-1}$; Amersham Life Science, Arlington Heights, IL). Substrate concentrations were consistent across experiments for each combination of radiolabels and for both in vivo- and in vitro-derived embryos. Labelled substrates were dried under nitrogen gas, reconstituted in the metabolism medium described above and allowed to equilibrate at $38.5^{\circ} \mathrm{C}$ in $5 \% \mathrm{CO}_{2}$ in air. Both in vivo- and in vitro-derived embryos were washed and held briefly in metabolism medium before measurement of metabolism. Embryos were taken up individually in $2 \mu \mathrm{l}$ metabolism medium, combined with $2 \mu \mathrm{l}$ of medium containing the labelled substrates and placed in the cap of a $1.5 \mathrm{ml}$ microcentrifuge tube (Fisher, Pittsburgh, PA). The cap was placed on top of the tube containing $1.5 \mathrm{ml}$ of $25 \mathrm{mmol}$ warmed sodium bicarbonate solution $\mathrm{I}^{-1}$, gassed with $5 \% \mathrm{CO}_{2}, 10 \% \mathrm{O}_{2}$ and $85 \% \mathrm{~N}_{2}$, and incubated for $3 \mathrm{~h}$ at $38.5^{\circ} \mathrm{C}$. Sham and total count tubes were prepared for each replicate in an identical manner, but containing no embryo. Total count tubes were shaken before incubation.

After the $3 \mathrm{~h}$ incubation, the caps were removed and $1.0 \mathrm{ml}$ of the sodium bicarbonate was placed into a scintillation vial containing $200 \mu \mathrm{l}$ of $0.1 \mathrm{mmol} \mathrm{NaOH} \mathrm{I} \mathrm{I}^{-1}$ and refrigerated at $4^{\circ} \mathrm{C}$ for $16-20 \mathrm{~h}$. Blastocyst and morula stage embryos were recovered for determination of the number of cells. Scintillation fluid $(10 \mathrm{ml}$ per vial; Ecolite, ICN, Costa Mesa, CA) was added and vials were counted for $4 \mathrm{~min}$ with a scintillation counter programmed for duallabel counting. The amount of substrate metabolized by each embryo was calculated as described by Tiffin et al. (1991), accounting for concentrations of labelled and unlabelled substrates.

\section{Cell counts}

Morula and blastocyst stage embryos were stained with $0.1 \mathrm{mg}$ Hoechst 33342 DNA stain $\mathrm{ml}^{-1}$ (Pursel et al., 1985) for 20 min and cells were counted at $\times 200$ magnification with an inverted Nikon microscope using UV light.

\section{Statistical analysis}

The data were analysed using GLM ANOVA. If variances were not homogeneous, as determined by the modified Levene equal variance test, the data were log-transformed before analysis. Differences were determined using a Bonferroni multiple comparison test for normally distributed data, or a Kruskal-Wallis multiple comparison test for non-normally distributed data. The level of significance was $P<0.05$. Data are mean \pm SEM.

\section{Results}

In vitro-derived embryos had reduced metabolic activity at all of the cell stages examined compared with in vivoderived embryos when assayed under the conditions described. Both in vitro- and in vivo-derived pig embryos had increased glycolytic activity throughout preimplantation development (Table 1). Glucose metabolism via glycolysis was used preferentially compared with other substrates and pathways at all cell stages examined in in vivo-derived embryos, whereas this was true only after the two-cell stage in in vitro-derived embryos. On a per cell basis, glycolytic activity decreased as development progressed in both in vitro- and in vivo-derived embryos (Table 1). However, glycolytic activity was significantly higher at all stages in in vivo-derived pig embryos compared with in vitro-derived embryos (Fig. 1a). Glucose metabolism of in vitro-derived embryos through glycolysis occurred in significant amounts at all cell stages examined and showed significant increases at both the morula and blastocyst stages (Table 1), whereas glucose metabolism of in vivoderived embryos increased significantly at the blastocyst stage only (Table 1).

The metabolism of glucose via the Krebs cycle in in vivoderived embryos increased significantly at the morula stage and remained high in blastocysts (Table 2). At the two-cell stage, metabolism of glucose via the Krebs cycle was similar between in vitro- and in vivo-derived embryos (Fig. 1b). However, as development progressed, in vivo-derived embryos used more glucose oxidatively than did in vitroderived embryos (Fig. 1b). Glucose was metabolized equally in the Krebs cycle and glycolysis by in vitro-derived pig embryos at the two-cell stage. However, glycolysis became the preferred pathway as development progressed. In in vivo-derived embryos, glycolysis was the preferred pathway at every cell stage examined. Metabolism of glucose via the Krebs cycle by in vitro-derived embryos remained constant throughout development (Table 2) and increased at the morula stage in in vivo-derived embryos (Table 2). Glucose use per cell via the Krebs cycle 
Table 1. Glucose metabolism via glycolysis and pyruvate metabolism via the Krebs cycle during preimplantation development of in vitroand in vivo-derived pig embryos

\begin{tabular}{|c|c|c|c|c|c|c|}
\hline \multirow[b]{2}{*}{$\begin{array}{l}\text { Stage of } \\
\text { development }\end{array}$} & \multirow[b]{2}{*}{$n$} & \multicolumn{2}{|c|}{ Glycolysis $\left(\left[5-{ }^{3} \mathrm{H}\right]\right.$ glucose $)$} & \multicolumn{2}{|c|}{ Krebs cycle ([2-14C] pyruvate) } & \multirow[b]{2}{*}{$\begin{array}{l}\text { Number of } \\
\text { cells } \pm \text { SEM }\end{array}$} \\
\hline & & $\begin{array}{l}\text { pmol embryo }^{-1} \\
\qquad(3 \mathrm{~h})^{-1}\end{array}$ & $\begin{array}{l}\text { pmol cell-1 }^{-1} \\
\qquad(3 \mathrm{~h})^{-1}\end{array}$ & $\begin{array}{l}\text { pmol embryo }^{-1} \\
\qquad(3 \mathrm{~h})^{-1}\end{array}$ & $\begin{array}{l}\text { pmol cell-1 } \\
(3 \mathrm{~h})^{-1}\end{array}$ & \\
\hline \multicolumn{7}{|c|}{ In vitro-derived } \\
\hline Two-cell & 12 & $2.24 \pm 0.46^{\mathrm{a}}$ & $1.12 \pm 0.23^{a}$ & $0.30 \pm 0.07^{a}$ & $0.15 \pm 0.03^{a}$ & 2 \\
\hline Eight-cell & 21 & $3.82 \pm 0.43^{a}$ & $0.48 \pm 0.05^{b}$ & $0.38 \pm 0.07^{a}$ & $0.05 \pm 0.01^{b}$ & 8 \\
\hline Morula & 32 & $7.19 \pm 0.82^{b}$ & $0.29 \pm 0.03^{c}$ & $0.47 \pm 0.07^{a b}$ & $0.02 \pm 0.002^{c}$ & $25.25 \pm 2.86$ \\
\hline Blastocyst & 41 & $12.47 \pm 1.05^{c}$ & $0.30 \pm 0.03^{c}$ & $0.57 \pm 0.05^{b}$ & $0.01 \pm 0.001^{c}$ & $47.24 \pm 0.68$ \\
\hline \multicolumn{7}{|l|}{ In vivo-derived } \\
\hline Two-cell & 4 & $16.27 \pm 6.19^{\mathrm{ab}}$ & $8.13 \pm 3.10^{\mathrm{a}}$ & $0.49 \pm 0.17^{a}$ & $0.25 \pm 0.086^{\mathrm{a}}$ & 2 \\
\hline Eight-cell & 14 & $18.20 \pm 1.76^{\mathrm{a}}$ & $2.28 \pm 0.22^{\mathrm{a}}$ & $1.02 \pm 0.13^{a}$ & $0.13 \pm 0.016^{\mathrm{a}}$ & 8 \\
\hline Morula & 24 & $19.40 \pm 1.59^{a}$ & $0.77 \pm 0.07^{b}$ & $1.11 \pm 0.16^{\mathrm{a}}$ & $0.04 \pm 0.006^{b}$ & $27.44 \pm 1.34$ \\
\hline Blastocyst & 30 & $53.02 \pm 7.87^{b}$ & $0.94 \pm 0.14^{b}$ & $1.96 \pm 0.22^{b}$ & $0.03 \pm 0.004^{b}$ & $63.53 \pm 5.43$ \\
\hline
\end{tabular}

${ }^{\text {a-c } D i f f e r e n t ~ s u p e r s c r i p t s ~ i n d i c a t e ~ s i g n i f i c a n t ~ d i f f e r e n c e s ~ w i t h i n ~ a ~ c o l u m n ~ a n d ~ w i t h i n ~ a ~ g r o u p ~(i n ~ v i t r o-~ o r ~ i n ~ v i v o-d e r i v e d ~ e m b r y o s) ~}(P<0.05)$.
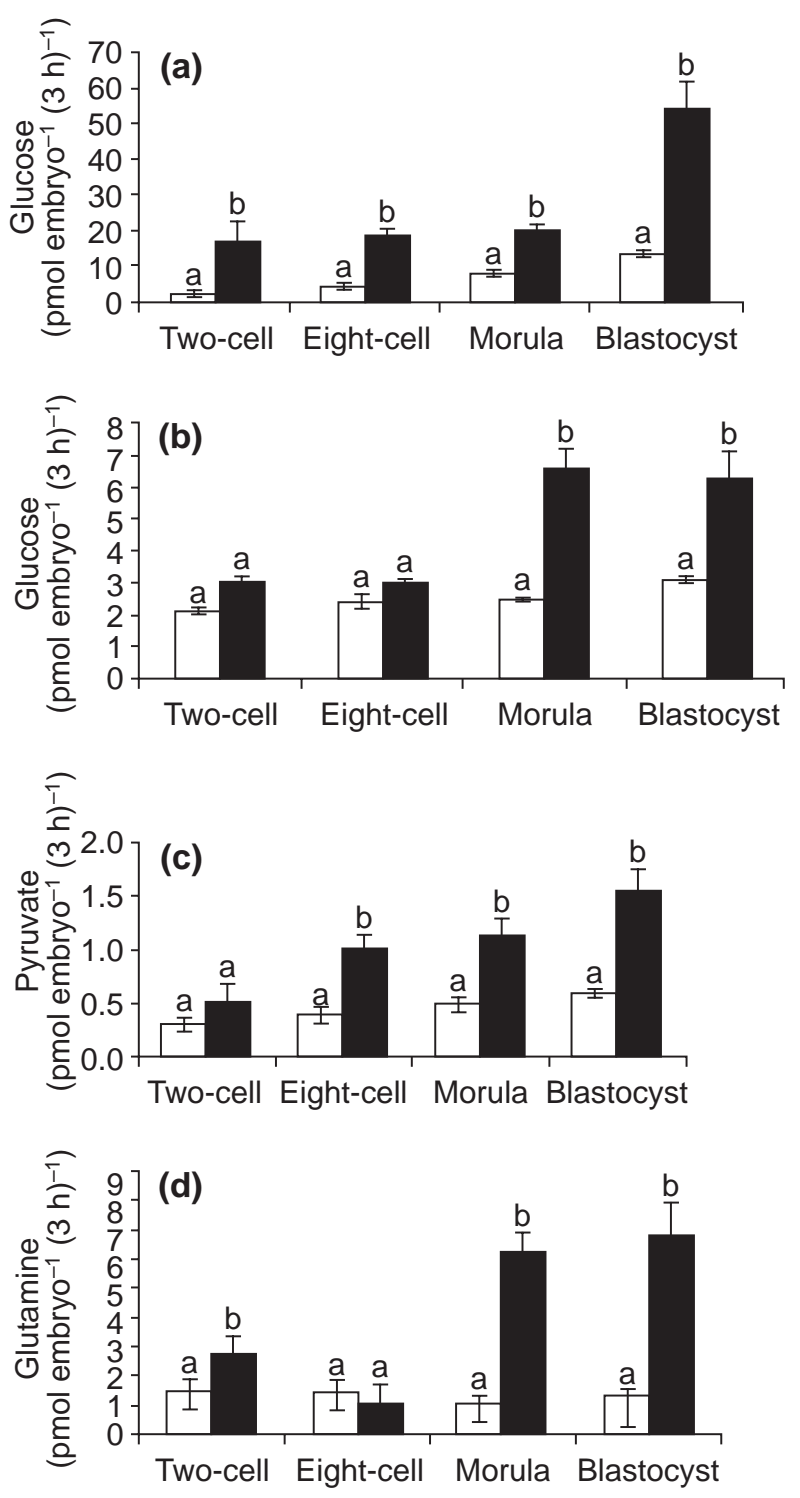

decreased throughout development in both in vivo- and in vitro-derived embryos (Table 2).

In vivo-derived pig embryos used minimal amounts of pyruvate at all cell stages examined (Table 1). Significant increases per embryo were observed at the blastocyst stage only (Table 1). Pyruvate metabolism by in vivo-derived embryos decreased on a per cell basis at the morula stage (Table 1). After the two-cell stage, pyruvate use by in vivoderived pig embryos was higher than the use by in vitro-derived pig embryos (Fig. 1c). Pyruvate use by in vitroderived pig embryos was also minimal throughout preimplantation development (Table 1). As in in vivoderived embryos, a significant increase in pyruvate metabolism occurred in in vitro-derived embryos at the blastocyst stage (Table 1). Use of pyruvate by in vitroderived embryos on a per cell basis decreased throughout development (Table 1).

In vivo-derived pig embryos significantly increased glutamine metabolism through the Krebs cycle at the morula stage (Table 2). In vivo-derived pig embryos used greater amounts of glutamine than did in vitro-derived embryos at all stages except for the eight-cell stage (Fig. 1d). Glutamine metabolism by in vitro-derived embryos showed no significant changes throughout development on a per embryo basis, but decreased throughout development when evaluated on a per cell basis (Table 2).

The numbers of cells were similar for both in vivo- and in vitro-derived morula stage pig embryos. However, in vivoderived blastocysts had significantly higher numbers of cells than did in vitro-derived blastocysts. Thus, comparisons of

Fig. 1. Differences in use of (a) glucose in glycolysis, (b) glucose in the Krebs cycle, (c) pyruvate and (d) glutamine during preimplantation development in pig embryos derived in vitro ( $\square$ ) and in vivo $(\boldsymbol{\square})$. Values are mean \pm SEM. abDifferent superscripts indicate significant differences between embryo sources within a cell stage $(P<0.05)$. 
Table 2. Glucose and glutamine metabolism via the Krebs cycle during preimplantation development of in vitro- and in vivo-derived pig embryos

\begin{tabular}{|c|c|c|c|c|c|c|}
\hline \multirow[b]{2}{*}{$\begin{array}{l}\text { Stage of } \\
\text { development }\end{array}$} & \multirow[b]{2}{*}{$n$} & \multicolumn{2}{|c|}{ Krebs cycle $\left(\left[6-{ }^{14} \mathrm{C}\right]\right.$ glucose $)$} & \multicolumn{2}{|c|}{ Krebs cycle $\left(\left[2,3,4{ }^{3} \mathrm{H}\right]\right.$ glutamine $)$} & \multirow[b]{2}{*}{$\begin{array}{l}\text { Number of } \\
\text { cells } \pm \text { SEM }\end{array}$} \\
\hline & & $\begin{array}{l}\text { pmol embryo }{ }^{-1} \\
\qquad(3 \mathrm{~h})^{-1}\end{array}$ & $\begin{array}{l}\text { pmol cell }^{-1} \\
\qquad(3 \mathrm{~h})^{-1}\end{array}$ & $\begin{array}{l}\text { pmol embryo }{ }^{-1} \\
(3 \mathrm{~h})^{-1}\end{array}$ & $\begin{array}{l}\text { pmol cell }^{-1} \\
\quad(3 \mathrm{~h})^{-1}\end{array}$ & \\
\hline \multicolumn{7}{|c|}{ In vitro-derived } \\
\hline Two-cell & 9 & $2.08 \pm 0.43^{\mathrm{a}}$ & $1.04 \pm 0.22^{\mathrm{a}}$ & $1.48 \pm 0.09^{a}$ & $0.74 \pm 0.05^{\mathrm{a}}$ & 2 \\
\hline Eight-cell & 16 & $2.37 \pm 0.41^{\mathrm{a}}$ & $0.30 \pm 0.05^{\mathrm{ab}}$ & $1.39 \pm 0.23^{a}$ & $0.17 \pm 0.03^{b}$ & 8 \\
\hline Morula & 16 & $2.41 \pm 0.21^{\mathrm{a}}$ & $0.09 \pm 0.01^{b}$ & $1.01 \pm 0.08^{\mathrm{a}}$ & $0.04 \pm 0.004^{c}$ & $26.2 \pm 0.92$ \\
\hline Blastocyst & 20 & $2.96 \pm 0.28^{a}$ & $0.06 \pm 0.01^{\mathrm{c}}$ & $1.29 \pm 0.12^{\mathrm{a}}$ & $0.03 \pm 0.002^{\mathrm{c}}$ & $56.1 \pm 4.48$ \\
\hline \multicolumn{7}{|l|}{ In vivo-derived } \\
\hline Two-cell & 9 & $3.01 \pm 0.66^{\mathrm{ab}}$ & $1.50 \pm 0.33^{\mathrm{a}}$ & $2.66 \pm 0.16^{\mathrm{ab}}$ & $1.33 \pm 0.08^{\mathrm{a}}$ & 2 \\
\hline Eight-cell & 17 & $2.91 \pm 0.65^{\mathrm{a}}$ & $0.36 \pm 0.08^{b}$ & $1.01 \pm 0.16^{b}$ & $0.13 \pm 0.02^{b}$ & 8 \\
\hline Morula & 48 & $6.47 \pm 0.67^{b}$ & $0.25 \pm 0.03^{b}$ & $6.17 \pm 0.63^{\mathrm{ac}}$ & $0.23 \pm 0.03^{b}$ & $27.29 \pm 1.07$ \\
\hline Blastocyst & 25 & $6.19 \pm 1.12^{b}$ & $0.10 \pm 0.02^{\mathrm{c}}$ & $6.74 \pm 0.64^{c}$ & $0.11 \pm 0.01^{b}$ & $67.92 \pm 3.88$ \\
\hline
\end{tabular}

${ }^{\mathrm{a}-\mathrm{c} D}$ Different superscripts indicate significant differences within a column and within a group (in vitro- or in vivo-derived embryos) $(P<0.05)$.

metabolic parameters at this stage are most meaningful when compared on a per cell basis.

\section{Discussion}

Comparison of the metabolic activity of pig embryos derived in vitro and in vivo provides useful information to assess the efficiency of in vitro systems for production of pig embryos. The results of the present study indicate that developing in vitro-derived pig embryos display metabolism that is significantly different from that of in vivoderived embryos when measured under in vitro assay conditions. In vivo-derived pig embryos use greater amounts of energy substrates than do in vitro-derived embryos in the pathways examined, particularly at the morula and blastocyst stages. Metabolism of endogenous energy stores, such as glycogen and lipid, cannot be assessed using these techniques and may also play a part in energy production in pig embryos.

Under the assay conditions described in the present study, in vivo-derived pig embryos used significantly more glucose via glycolysis than did in vitro-derived pig embryos at all the cell stages examined. Regardless of embryo source, glycolysis is the predominant metabolic pathway used by developing preimplantation pig embryos. However, more energy is derived for cellular processes by metabolism of glucose via the Krebs cycle. These findings indicate that glycolytic metabolism of glucose may be important to embryos for reasons other than energy production. Metabolism through the pentose phosphate pathway (PPP) is regulated by the flux of glucose through glycolysis. The pentose phosphate pathway, although it does not generate ATP, has several critical functions in the cell. It is responsible for metabolizing glucose, generating ribose 5-phosphate and NADPH. Ribose 5-phosphate is converted to phosphoribosylpyrophosphate (PRPP), a compound needed for the synthesis of purines and for the salvage pathways. In addition, one of the mechanisms that protects cells against harmful oxidants is the glutathione peroxidase reaction. Glutathione peroxidase catalyses the reduction of hydrogen peroxide via reduced glutathione to produce water. NADPH then reduces the resulting oxidized glutathione in a reaction catalysed by glutathione reductase. The pentose phosphate pathway is responsible for using this $\mathrm{NADP}^{+}$to generate more NADPH so that glutathione can be maintained in the reduced state. Pig embryos increase activity of the PPP starting at the morula stage, although as a percentage of total glucose use, PPP activity decreased throughout development (Flood and Wiebold, 1988).

In other species such as mice (Biggers et al., 1967; Leese et al., 1984), cows (Rieger et al., 1992a,b; Kim et al., 1993), sheep (Gardner et al., 1993) and humans (Hardy et al., 1989; Conaghan et al., 1993), lactate and pyruvate are the preferred energy substrates at early cleavage stages. Glucose use in these species is limited until after compaction and glucose has been found to be inhibitory when present before this time (Schini and Bavister, 1988b; Thompson et al., 1992; Kim et al., 1993). However, the results of the present study show that pig embryos metabolize glucose throughout preimplantation development and that in vivo-derived pig embryos metabolize more glucose than do in vitro-derived embryos. Our findings support a previous report of glucose metabolism by pig embryos in vivo (Flood and Weibold, 1988). These findings indicate that glucose is important throughout development of pig embryos. Previous studies indicating an inhibitory effect of glucose on pig embryonic development (Youngs and McGinnis, 1990; Misener et al., 1991) were performed with a combination of glucose and lactate, which may account for the inhibitory effect observed, as it was previously reported that lactate was inhibitory to development of pig embryos (Davis and Day, 1978; Davis, 
1985). The amounts of glucose used via glycolysis by both in vitro- and in vivo-derived pig embryos in the present study were lower than those reported by Flood and Weibold (1988). This discrepancy may be the result of differences in metabolic measurement technique, including differences in substrate concentration in metabolic measurement medium, which is known to influence metabolism (for a review, see Barnett and Bavister, 1996a,b). Regardless, it is evident that the metabolism of pig embryos is markedly different from that of other species, as pig embryos use glucose as the primary energy substrate throughout preimplantation development.

Flood and Weibold (1988) suggested that the increase in glycolytic activity of pig embryos could be the result of inadequate amounts of glucose uptake to allow sufficient phosphorylation of glucose to glucose- 6 -phosphate at early cleavage stages. This is probably not the case because comparison of our results with those of a previous study (Gandhi et al., 2001), in which substrate uptake of pig embryos was examined, indicates that pig embryos use only a fraction of the glucose they take up. Flood and Weibold (1988) suggested that there might be inadequate hexokinase activity in early cleavage stage embryos to support increased glycolytic rates. In other species, it appears that hexokinase activity is sufficient to support glycolysis throughout development (Chi et al., 1988; Martin et al., 1993). Instead, glycolysis probably increases as development progresses, as the result of the release of inhibition of phosphofructokinase (PFK) activity. In mouse embryos, ATP concentrations decrease throughout development as the energy demands of the embryo increase (Quinn and Wales, 1971). ATP inhibits phosphofructokinase and, thus, decreasing ATP concentration results in increased phosphofructokinase activity.

The difference in glucose use through glycolysis and the Krebs cycle by both in vitro- and in vivo-derived embryos observed under in vitro assay conditions in the present study indicates that some of the pyruvate derived by glycolysis may be converted to lactate by the embryo. Gandhi et al. (2001) reported increasing lactate production by in vitro-derived pig embryos as development progressed. Bovine (Khurana and Niemann, 2000) and murine (Lane and Gardner, 1996) embryos produced in vitro have increased lactate production compared with in vivoderived embryos. Production of lactate by the embryo may be used to regulate intracellular $\mathrm{pH}$ or to adjust the NAD:NADH ratio. Lactate may also have a physiological role in the in vivo environment, as lactate concentrations in pig oviductal fluid are higher than the concentrations of pyruvate or glucose (Nichol et al., 1992). In vivo-derived pig embryos have been cultured successfully in the presence of lactate (Youngs and McGinnis, 1990; Misener et al., 1991; Dobrinsky et al., 1996) and lactate increased development of IVM-IVF pig embryos (Iwasaki et al., 1999). Thus, lactate, both derived by the embryo and present in the milieu, may be important for development of pig embryos.

Pyruvate is not required for development of pig embryos
(Petters et al., 1990; Petters and Reed, 1991). The results of the present study support this conclusion, as metabolism of pyruvate remained minimal throughout all stages of preimplantation development. The concentration of pyruvate in the metabolism medium may influence the metabolism of pyruvate, which may explain why in vitro-derived embryos metabolized less pyruvate than did in vivo-derived embryos, as there is no pyruvate in NCSU23 culture medium. Pyruvate was included in the medium used for measurement of metabolism to assess the capability of embryos from both sources to metabolize this substrate. In contrast, Gandhi et al. (2001) reported significant uptake of pyruvate at the morula and blastocyst stages. It is possible that, in vitro, pyruvate is being taken up from the culture medium by the embryo and converted to lactate, instead of being metabolized through the Krebs cycle. Pyruvate use was higher in in vivo-derived embryos, indicating that some pyruvate is being metabolized. It is possible that the necessary requirement for pyruvate is met by the metabolism of glucose. However, pyruvate is an antioxidant and may offer the embryo protection against the stress of the environment in vitro (O'Fallon and Wright, 1995).

There are conflicting reports about the effects of certain combinations of amino acids on development of pig embryos (Stone et al., 1984; Meyen et al., 1989; Rosenkrans et al., 1989; Kim et al., 1993). Glutamine is beneficial for pig embryonic development and can support development to the blastocyst stage, alone or in combination with glucose (Petters et al., 1990). In the present study, glutamine use through the Krebs cycle by in vitro-derived pig embryos remained constant throughout development. However, glutamine use by in vivo-derived pig embryos increased as development proceeded. This observation indicates that there may be a deficiency in the concentrations of glutamine in the culture medium or in the enzymes necessary for glutamine uptake or metabolism by in vitroderived pig embryos. Gardner and Lane (1993) suggested that amino acids act as osmoregulators, osmoprotectants, $\mathrm{pH}$ regulators and energy sources for preimplantation embryos. The addition of specific amino acids to culture medium enhances development of pig embryos (Petters and Reed, 1991). However, pig embryos can develop to the blastocyst stage in the absence of amino acids (Petters and Wells, 1993). Although amino acids are not required, it appears that glutamine is beneficial and serves some role in normal pig embryonic development.

This is the first study in which the metabolic activity of in vitro- and in vivo-derived pig embryos has been examined throughout preimplantation development. Pig embryos derived in vitro with current culture techniques have significantly altered metabolic activity compared with in vivoderived embryos. Altered metabolic activity may be indicative of suboptimal in vitro maturation, fertilization or culture conditions. Using the available metabolic data to formulate a more appropriate culture medium specifically for pig embryos will be of benefit for emerging biotechnologies. 
The authors would like to thank Indiana Packers for their generous donation of pig ovaries, Aaron Johnson and Rachel Durkin for transportation of ovaries, the staff of the swine unit at the Purdue Animal Science Research and Education Center for collection of boar semen, and the following members of the laboratory of Matthew Wheeler in the Department of Animal Sciences, University of Illinois for their assistance in collection of in vivo-derived embryos: Julie Cook, Melissa Hentges, Kilby Willenburg, Kelly O'Callaghan and Kevin Jackson.

\section{References}

Abeydeera LR and Day BN (1997) Fertilization and subsequent development in vitro of pig oocytes inseminated in a modified Trisbuffered medium with frozen-thawed ejaculated spermatozoa Biology of Reproduction 57 729-734

Abeydeera LR, Wang WH, Prather RS and Day BN (1998) Maturation in vitro of pig oocytes in protein-free culture media: fertilization and subsequent embryo development in vitro. Biology of Reproduction $\mathbf{5 8}$ 1316-1320

Barnett DK and Bavister BD (1996a) Inhibitory effect of glucose and phosphate on the second cleavage division of hamster embryos: is it linked to metabolism? Human Reproduction Update 191-148

Barnett DK and Bavister BD (1996b) What is the relationship between the metabolism of preimplantation embryos and their developmental competence Molecular Reproduction and Development 43 105-133

Biggers JD, Whittingham DG and Donahue RP (1967) The pattern of energy metabolism in the mouse oocyte and zygote Proceedings National Academy of Sciences USA 58 560-567

Carney EW and Bavister BD (1987) Stimulatory and inhibitory effects of amino acids on the development of hamster eight cell embryos in vitro. Journal of In Vitro Fertilization and Embryo Transfer 4 162-167

Chatot CL, Ziomek CA, Bavister BD, Lewis JL and Torres I (1989) An improved culture medium supports development of random bred 1-cell mouse embryos in vitro. Journal of Reproduction and Fertility $\mathbf{8 6}$ 679-688

Chatot CL, Tasca RJ and Ziomek CA (1990) Glutamine uptake and utilization by preimplantation mouse embryos in CZB medium Journal of Reproduction and Fertility 89 335-346

Chi MMY, Manchester JY, Yang VC, Curato AD, Stirckler RC and Lowry OH (1988) Contrast in levels of metabolic enzymes in human and mouse ova Biology of Reproduction 39 295-301

Conaghan J, Hardy K, Handyside AH, Winston RML and Leese HJ (1993) Effects of pyruvate and glucose on the development of human preimplantation embryos in vitro. Journal of Reproduction and Fertility 99 87-95

Davis DL (1985) Culture and storage of pig embryos Journal of Reproduction and Fertility Supplement 33 115-124

Davis DL and Day BN (1978) Cleavage and blastocyst formation by pig eggs in vitro. Journal of Animal Science 46 1043-1053

Dobrinsky JR, Johnson LA and Rath D (1996) Development of a culture medium (BECM-3) for porcine embryos: effects of bovine serum albumin and fetal bovine serum on embryo development Biology of Reproduction 55 1069-1074

Flood MR and Weibold JL (1988) Glucose metabolism by preimplantation pig embryos Journal of Reproduction and Fertility 84 7-12

Gandhi AP, Lane M, Gardner DK and Krisher RL (2001) Substrate utilization in porcine embryos cultured in NCSU23 and G1.2/G2.2 sequential culture media Molecular Reproduction and Development 58 $269-275$

Gardner DK and Lane M (1993) Amino acids and ammonium regulate mouse embryo development in culture Biology of Reproduction $\mathbf{4 8}$ 377-385

Gardner DK and Leese HJ (1990) Concentrations of nutrients in mouse oviduct fluid and their effects on embryo development and metabolism in vitro. Journal of Reproduction and Fertility 88 361-368

Gardner DK, Clarke RN, Lechene CP and Biggers JD (1989) Development of a noninvasive ultra microfluorometric method for measuring net uptake of glutamine by single preimplantation mouse embryos Gamete Research 24 427-438

Gardner DK, Lane M and Batt P (1993) Uptake and metabolism of pyruvate and glucose by individual sheep preattachment embryos developed in vivo. Molecular Reproduction and Development 36 361-368

Hardy K, Hooper MA, Handyside AH, Tutherford AJ, Winston RM and Leese HJ (1989) Non invasive measurement of glucose and pyruvate uptake by individual human oocytes and preimplantation embryos Human Reproduction 4 188-191

Iwasaki T, Kimura E and Totsukawa K (1999) Studies on a chemically defined medium for in vitro culture of in vitro matured and fertilized porcine oocytes Theriogenology $\mathbf{5 1} 709-720$

Khurana NK and Niemann H (2000) Energy metabolism in preimplantation bovine embryos derived in vitro or in vivo. Biology of Reproduction $\mathbf{6 2}$ 847-856

Kim JH, Niwa K, Lim JM and Okuda K (1993) Glucose requirements at different developmental stages of in vitro fertilized bovine embryos cultured in semi defined medium Theriogenology 39 875-886

Lane M and Gardner DK (1996) Selection of viable mouse blastocysts prior to transfer using metabolic criterion Human Reproduction 11 1975-1978

Leese HJ and Barton AM (1984) Pyruvate and glucose uptake by mouse ova and preimplantation embryos Journal of Reproduction and Fertility $\mathbf{7 2}$ 9-13

McKiernan SH, Bavister BD and Tasca RJ (1991) Energy substrate requirements for in vitro development of hamster 1 and 2 cell embryos to the blastocyst stage Human Reproduction 6 64-75

Martin KL, Hardy K, Winston RML and Leese HJ (1993) Activity of enzymes of energy metabolism in single human preimplantation embryos Journal of Reproduction and Fertility 99 259-266

Meyen BA, Rosenkrans CF and Davis DL (1989) Development of pig blastocysts in vitro is altered by serum bovine albumin and amino acids and vitamins Theriogenology 31 463-471

Misener M, Pollard JW and Metzger K (1991) In vitro culture of porcine embryos in CZB medium Theriogenology 35244 (Abstract)

Nichol R, Hunter HF, Gardner DK, Leese HJ and Cooke GM (1992) Concentrations of energy substrates in oviductal fluid and blood plasma of pigs during the peri-ovulatory period Journal of Reproduction and Fertility 96 669-707

O'Fallon JV and Wright RW, Jr (1986) Quantitative determination of the pentose phosphate pathway in preimplantation mouse embryos Biology of Reproduction 34 58-64

O'Fallon JV and Wright RW, Jr (1995) Pyruvate revisited: a non metabolic role for pyruvate in preimplantation embryo development Theriogenology 43288 (Abstract)

Petters RM and Reed ML (1991) Addition of taurine or hypotaurine to culture medium improves development of one and two cell pig embryos in vitro. Theriogenology 35253 (Abstract)

Petters RM and Wells KD (1993) Culture of pig embryos Journal of Reproduction and Fertility 48 61-73

Petters RM, Johnson BH, Reed ML and Archibong AE (1990) Glucose, glutamine and inorganic phosphate in early development of the pig embryo in vitro. Journal of Reproduction and Fertility $89269-275$

Pursel VG, Wall RJ and Rexroad CE (1985) A rapid whole mount staining procedure for the nuclei of mammalian embryos Theriogenology $\mathbf{2 4}$ 682-691

Quinn P and Wales RG (1971) Adenosine triphosphate content of preimplantation mouse embryos Journal of Reproduction and Fertility 25 133-135

Renard JP, Philippin A and Menezo Y (1980) In vitro glucose uptake of glucose by bovine blastocysts Journal of Reproduction and Fertility $\mathbf{5 8}$ 161-164

Rieger D, Loskutoff NM and Betteridge KJ (1992a) Developmentally related changes in the metabolism of glucose and glutamine by cattle embryos produced and co-cultured in vitro. Journal of Reproduction and Fertility 95 585-595

Rieger D, Loskutoff NM and Betteridge KJ (1992b) Developmentally related changes in the uptake and metabolism of glucose, glutamine and 
pyruvate by cattle embryos produced in vitro. Reproduction, Fertility and Development 4 547-557

Rosenkrans CF, Zeng GQ, McNamara GT, Schoff PK and First NL (1993) Development of bovine embryos in vitro as affected by energy substrates Biology of Reproduction 49 459-462

Schini SA and Bavister BD (1988a) Two-cell block to development of cultured hamster embryos is caused by phosphate and glucose Biology of Reproduction 39 1183-1192

Schini SA and Bavister BD (1988b) Development of golden hamster embryos through the two cell block in chemically defined medium Journal of Experimental Zoology 245 111-115

Seshagiri PB and Bavister BD (1989) Glucose inhibits development of hamster 8-cell embryos in vitro. Biology of Reproduction 40 599-606

Stone BA, Quinn P and Seamark RF (1984) Energy and protein sources for development of pig embryos cultured beyond hatching in vitro. Animal Reproduction Science 7 405-412

Thompson JG (1997) Comparison between in vivo derived and in vitro produced pre-elongation embryos from domestic ruminants Reproduction, Fertility and Development 9 341-354

Thompson JG, Simpson AC, Pugh PA, Pugh RW, Jr and Tervit HR (1991)
Glucose utilization in sheep embryos derived in vivo and in vitro. Reproduction, Fertility and Development 3 571-576

Thompson JG, Simpson AC, Pugh PA and Tervit HR (1992) Requirement for glucose during in vitro culture of sheep preimplantation embryos Molecular Reproduction and Development 31 253-257

Tiffin G, Rieger D, Betteridge KJ, Yadav BR and King WA (1991) Glucose and glutamine metabolism in pre-attachment cattle embryos in relation to sex and stage of development Journal of Reproduction and Fertility 93 124-132

Youngs CR and McGinnis LK (1990) In vitro culture of porcine embryos in Whitten's medium containing varying levels of glucose and bovine serum albumin Biology of Reproduction 4258 (Abstract)

Received 4 May 2001.

First decision 4 June 2001.

Final manuscript received 26 October 2001.

Accepted 29 October 2001. 